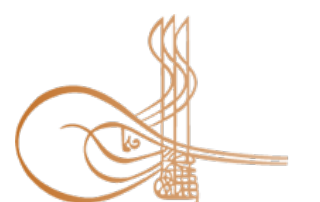

www.turkishstudies.net/social
Turkish Studies - Social Sciences

eISSN: 2667-5617

Research Article / Araştırma Makalesi

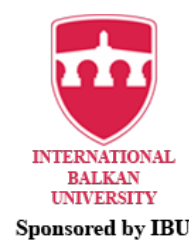

Sponsored by IBU

\title{
Çok Kriterli Karar Verme Yöntemlerinin Seçimi Üzerine Bir Değerlendirme: TOPSIS Örneği
}

\author{
An Evaluation on the Selection of Multi-Criteria Decision-Making Methods: TOPSIS Example
}

\author{
Çiğdem Özarı ${ }^{*}$
}

\begin{abstract}
In this study, a hypothetical problem was assessed in order to contribute to the new studies to be carried out by TOPSIS (Technique for Order Preference by Similarity to Ideal Solution), which is one of the Multi-Criteria Decision Making methods and to provide conceptual basis, process and applications of the TOPSIS method more efficiently. It is obvious that these methods may lead different results when the researcher apply different importance degrees to criteria or use differnet normalization technique. The main purpose of the study is to indicate that the alternatives (individuals) with the same weighted average scores are in different order when the researcher applies TOPSIS method. Evaluation results from sample problem, it was seen that the people with the same weighted average scores (alternatives) were in the different orders when the process is calculated by TOPSIS method. The sample problem, which is constructed through appropriate personnel selection or staff performance evaluation, appears to be problematic in the literature on many areas because of its structure. It has been emphasized in the research that method selection is important and that the results obtained from different multi-criteria decision methods can not be enough to compare and evaluate the efficiency of the methods. It is more effective to determine the method or methods to be chosen according to the nature of the problematic or in the direction that can be meet the expectations of the researcher or the structure of alnertavies and criteria.
\end{abstract}

Structured Abstract: By the help of the Multi Criteria Decision Techniques, researchers or decision makers evaluate the alternatives with different properties based on more than one criteria that can be measurable. In this research, TOPSIS (Technique for Order Preference by Similarity to Ideal Solution) method, which is one of the multi-criteria models in decision making process, was evaluated with the help of a hypothetical (fictional) problem related to personnel selection. This method was firstly proposed by Hwang and Yoon (1981) and it is one of the most used method to rank the alternatives and also to determine the optimum choice. The main concept of this method is that the most preferred alternative should have the shortest distance from the positive ideal solution and the longest distance from the negative ideal solution. This concept is the most important feature that distinguishes TOPSIS method from other methods.

It is important to know when TOPSIS method is more accurate to use, as studies can be performed in many different areas with this method. The main purpose of the research is to indicate that the alternatives with the same weighted average scores are in different order when the researcher (decion maker) decided to apply TOPSIS method. It is obvious that these methods may lead different results when the researcher apply different importance degrees to each criteria or use differnet normalization technique. It is also difficult the decision

\footnotetext{
* Dr. Öğr. Üyesi, İstanbul Aydın Üniversitesi, İktisadi ve İdari Bilimler Fakültesi, Ekonomi ve Finans Bölümü Asst. Prof. Dr., İstanbul Aydın Univesrity, Faculty of Economics and Administrative Sciences, Economics and Finance. ORCID 0000-0002-2948-8957 cigdemozari@aydin.edu.tr, cozari@gmail.com

Cite as/ Atıf: Özarı, Ç. (2020). Çok kriterli karar verme yöntemlerinin seçimi üzerine bir değerlendirme: TOPSIS örneği. Turkish Studies - Social, 15(4), 2071-2081. https://dx.doi.org/10.29228/TurkishStudies.39684

Received/Geliș: 11 November/Kasım 2019

Accepted/Kabul: 22 June/Haziran 2020

Checked by plagiarism software

Copyright (C) INTAC LTD, Turkey 
maker to assign a appropriate degree of importance level for each criteria. The main purpose of the study is to indicate that the alternatives (individuals) with the same weighted average scores (of evaluation criteria) are in different order when the researcher applies TOPSIS method.

In the hypothetical problem created in this study, the manager has to decide to hire the best person by considering 10 criteria $\left(\mathrm{C}_{1}, \mathrm{C}_{2}, \ldots, \mathrm{C}_{10}\right)$ among five people $(\mathrm{A}, \mathrm{B}, \mathrm{C}, \mathrm{D}$ and $\mathrm{E})$. In other words, the problematic faced by the manager is to choose the most suitable candidate for the job by ranking the potential candidates from best to the worst accorging to the selected 10 criteria. This scenario and similar scenarios based on selection of best alternative are among the most frequently encountered problems in the literature in recruitment processes and/or performance evaluations.

In the hypothetical problem, the degrees of importance (weights) of the performance indicators that will be used to evaluate the performance of the candidates (people) are not equally distributed. In addition, a situation was created in which the weighted average scores of A, B and C candidates were equal, the weighted average score of $\mathrm{D}$ was the highest and the weighted average score of $\mathrm{E}$ was the lowest. The main purpose of this study is to state that the individuals with the same weighted average scores are ranked differently in the ranking obtained with the TOPSIS method, and to emphasize that such a situation is not desired, although it is not preferred to be in a different order in the ranking, although the same score is obtained in the weighted average.

In the hypothetical scenario, it is expected that $\mathrm{D}$ person will be in the first place (best), because the person has achieved superior success than other people by collecting better scores from most of the criteria. For person E, the scenario works in the opposite direction. The place of these two people in the ranking is obvious. However, although the weighted average scores of A, B and C people are the same; findings obtained from TOPSIS method, the person who scores only from a single criteria of high importance is ranked higher in the ranking. The point to be noted here is that the researcher or the decision maker chooses this method in practice considering this situation.

TOPSIS method makes evaluations by considering the proximity of positive ideal and negative ideal solutions without considering the comparison of criteria. It also determines this assessment with the help of distance function and does not consider the correlation between alternatives. In the research, it was emphasized once again that the choice of methods is very important due to the multitude of multi-criteria decision-making methods, and it was also emphasized that it would not be sufficient to compare and evaluate the efficiency by finding a few different methods. In summary, considering the frequent use of the method in many different areas in the literature, it was emphasized that it would be more appropriate to apply the method in cases where its structural features were harmonized by emphasizing the mathematical features in the method.

Keywords: Multi-Criteria Decision Methods, TOPSIS, Weighted Average, Importance Level, Personel Selection.

Öz: Bu çalışmada, Çok Kriterli Karar Verme yöntemlerinden biri olan TOPSIS (İdeal Çözüme Dayalı Sıralama Tekniği) ile gerçekleştirilecek yeni çalışmalara katkı sağlamak ve TOPSIS yönteminin kavramsal temeli, süreci ve uygulamalarının daha verimli yapılmasını sağlamak amacıyla kurgusal örnek bir problem değerlendirilmiştir. Bu yöntemlerde farklı önem dereceleri ve farklı normalizasyon teknikleri ile farklı sonuçlar elde edildiği aşikardır. Bu çalışmadaki ana amaç ağırlıklı ortalama puanları aynı olan alternatiflerin (kişilerin) TOPSIS yöntemi ile yapılacak olan sıralamada farklı sırada yer aldığını belirtmek ve böyle bir durumun istenmediği yani ağırlıklı ortalamada aynı puan alınmasına rağmen, sıralamada farklı sırada bulunmasının tercih edilmediği durumlar için uygulanmamasını vurgulamaktır. Bununla birlikte çok kriterli karar verme yöntemlerden hangisinin uygulanacağının karar verilmesinin önemli olduğunu vurgulamaktır. Değerlendirme sonucunda ağırlıklı ortalama puanları aynı olan alternatiflerin TOPSIS yöntemi ile oluşan sıralamada farklı sırada olduğu görülmüştür. Uygun personel seçimi ya da personel performans değerlendirilmesi üzerinden oluşturulan kurgusal örnek problem, yapısı gereği birçok alana yönelik literatürde benzer sorunsal olarak gözükmektedir. Araştırmada, çok kriterli karar verme yöntemlerinin çokluğu nedeniyle yöntem seçiminin çok önemli olduğu bir kez daha vurgulanarak, ayrıca bu yöntemlerle elde edilen bulgularda verimliliğin birkaç farklı yöntemle karşılaştırılarak sonuçlandırılıp değerlendirilmesinin de yeterli olamayacağı vurgulanmıştır.

Turkish Studies - Social, 15(4) 
Sorunsalın yapısına göre ya da araştırmacının beklentilerine cevap verebilecek doğrultuda ya da alternatiflerin ve kriterlerin sayısı ve yapısı doğrultusunda seçilecek yöntem veya yöntemlerin belirlenmesi daha etkilidir.

Anahtar Kelimeler: Çok Kriterli Karar Verme yöntemleri, TOPSIS, Önem Derecesi, Ağırlıklı Ortalama, Personel Seçimi.

\section{Giriş}

Çok Kriterli Karar Verme (ÇKKV) yöntemleri somut ve soyut kriterlere veya niteliklere göre potansiyel karar seçeneklerinden en iyisinin seçimiyle ilgilenir (Cho, 2003: 1099). ÇKKV yöntemleri genel olarak "Çok Amaçlı Karar Verme" ve "Çok Ölçütlü Karar Verme" olarak iki başlık altında incelenir. Çok amaçlı karar verme alternatiflerin bir matematiksel programlama yapısı içerisinde dolaylı olarak tanımlandığı ve sonsuz sayıda olduğu sürekli durumlarda karar vermeye dayanır (Ersöz \& Kabak, 2010: 101). Çok ölçütlü karar verme teknikleri ise süreksiz durumlarda yani elimizde sadece alternatiflerin ve kriterlerin dikkate alınarak gerçekleştirilen karar verme sürecidir. Karar verme sürecine destek olan bu yöntemler, genellikle farklı özelliklere sahip olan alternatiflerden en iyisinin seçiminde veya bu alternatiflerin en iyiden en kötüye siralanmasında kullanılır. Alternatifler farklı kişiler, ürünler, firmalar olarak değil de bir kişinin, ürünün ya da firmanın farklı zaman aralıkları olarak düşünüldüğünde ise örneğin bir firmanın belirli kriterler ya da değerlendirme faktörleri dikkate alınarak en iyi olduğu zamanı bulabilme ya da en iyi zamandan en kötü zamana doğru sıralanmasında kullanılabilir. Bir başka ifade ile ÇKKV yöntemleri genellikle performans ölçüm amacıyla kullanılır. Performans değerlendirilmesinde birçok farklı yöntem kullanılmaktadır. Çalışanların performansı çalıştıkları şirketlerin performansını da etkilediğinden benzeri çalışmalara literatürde sıkça rastlanmaktadır. Hangi yöntem kullanılırsa kullanılsın yapının kendi özelliğine uygun değerlendirme kriterleri belirlenmesi gerekir. Uygulanacak yöntemler ise şirketin kültürüne uygun olmakla birlikte uygulanabilir, ölçülebilir ve gerçeğe uygun olarak tasarlanmalıdır. Hesaplanan performans değerlendirilmeleriyle çalışanların başarı dereceleri belirlenerek, başarısız oldukları durumların belirlenmesi ve nedenlerinin araştırılması gerekir.

ÇKKV yöntemleri ile araştırmayı yapan kişiler ya da karar vericiler farklı özelliklere sahip olan alternatifleri birden fazla kritere göre değerlendirerek sıralamaktadırlar (Türkmen \& Çağıl, 2012: 63). Kriterlerin ölçüm birimleri de birbirinden farklılık gösterebilir, farklı ölçüm birimlerine sahip olan değerlendirme kriterleri dikkate alınarak alternatifleri siralamanın bir yolu ise alternatiflerin ikili olarak karşılaştırılmasıdır. ÇKVV yöntemlerinden olan ELECTRE (Elemination and Choice Translating Reality) ve PROMETHEE (Preference Ranking Organization Method for Encrichment Evaluations) gibi yöntemler ikili karşılaştırmalar yaparak değerlendirme gerçekleştirdiğinden, bu sorunu ortadan kaldırmak için bu ve benzeri yöntemlerden yararlanılabilir. Ancak ikili karşılaştırmaların yapılması alternatiflerin sayısının çok fazla olduğu durumlarda, yapılması gereken işlemlerin katlanarak artması ile sonuçlanmakta ve hızlı karar vermenin gerektiği dinamik piyasa koşullarında işletmenin karar vermede gecikmesine yol açabilmektedir (Özdağoğlu, 2013: 256). Bu sorunu ortadan kaldıran yöntemlerden biri de TOPSIS'dir. Bu yöntemde ise ikili karşılaştırmanın yerini normalizasyon işlemleri almaktadır. Literatürde farklı normalizasyon seçenekleri yer alır ve ÇKKV yöntemlerinde farklı normalizasyon yöntemleri kullanılabilir. Örneğin, TOPSIS yönteminde genellikle vektör normalizasyonu, VIKOR yönteminde ise genellikle doğrusal normalizasyon yöntemi kullanılır (Opricovic \& Tzeng, 2004: 450).

Wang'a göre ÇKKV yöntemleri Temel Yöntemler, Bir Değerli Birleştirilmiş Kriter Yöntemler ve Üstünlüğe Göre Sıralama Yöntemler başlıkları altında üç ana gruba ayrılmaktadır (Wang, 2009: 2273). Ağırlıklandırılmış toplama ve çarpım yöntemleri temel yöntemler grubunda, Analitik Hiyerarşi Süreci (AHP) ve TOPSIS ise bir değerli birleştirilmiş kriter yöntemler grubunda, ELECTRE ve PROMETHEE ikili karşılaştırmalarla değerlendirme yaptığından üstünlüğe göre siralama yöntemler grubunda yer almaktadır. 
Bir açıdan incelendiğinde doğrusal ağırlıklandırma tekniği olan TOPSIS yönteminin en önemli özelliği, bu yöntemde pozitif ideal çözüme en yakın ve negatif ideal çözüme en uzak olan en uygun çözümün belirlenmesidir (Çınar, 2010: 37). Bu mesafelerin iki yönlü olması ile sadece maksimize edilecek durumlar değil, minimize edilmesi gereken durumlar da göz önünde bulundurulur ve buna göre en uygun seçim yapılır (Özdemir \& Seçme, 2009: 83). Kısaca pozitif ideal çözüm kriterin ulaşabileceği en iyi değeri, negatif ideal çözüm kriterin ulaşabileceği en kötü değeri oluşturmaktadır (Ertuğrul \& Karakaşoğlu, 2009: 706-707). İdeal ya da pozitif ideal çözüm olarak ifade edilen çözüm, fayda kriterini maksimize eden, maliyet kriterini ise minimize eden çözümdür (Uzun \& Kazan, 2016: 101).

TOPSIS yöntemi ekonomi ve yönetim problemleri, muhasebe ve finans, sermaye yatırımı, karar destek, üretim, pazarlama, ürün tasarımı, planlama, portföy seçimi, risk analizi, başvuru değerlendirmeleri, grup karar verme, tesis yeri seçimi, kaynak tahsisi, politika/strateji, ulaştırma, eğitim, çevresel kararlar, sağlık, kamu sektörü, pazar seçimi, portföy seçimi, bilgisayar ve bilgi seçimi gibi benzer birçok alanlarda kullanılabilmektedir (Özkan, 2007: 124). TOPSIS yönteminin yoğunlukla tercih edilmesinin sebeplerinden bir tanesi de çok farklı alanlardaki çok ölçütlü karar problemlerinde karar vericiye destek olabilmesindendir (Koyuncu \& Özcan, 2014: 202). TOPSIS yöntemi kullanılarak yapılan çalışmalar aşağıda özetlenmektedir.

Demireli yapmış olduğu çalışmada 2001-2007 yılları arasındaki 7 yıllık dönemde Türkiye'de faaliyet gösteren ve ülke çapında yaygın olarak hizmet veren kamu sermayeli üç bankanın performansların 10 değerlendirme kriteri dikkate alarak TOPSIS performans değerlendirme sistemi ile sıralamıştır (Demireli, 2010). Çalışma sonucunda bankaların yerel ve global finansal krizlerden etkilendiği, performans puanlarının yurtdışı verilere dayalı olarak sürekli olarak dalgalanmalar gösterdiği, bankacılık sektöründe göze çarpan bir iyileşmenin kaydedilemediği saptanmıştır.

Dumanoğlu ve Ergül (2010); çalışmalarında 2006-2009 dönemi için BİST'da işlem gören 11 teknoloji şirketinin mali tablolarını değerlendirme kriterleri olarak ele alıp şirketlerin mali performanslarını TOPSIS yöntemi ile sıralamış, çalışmanın sonucunda ise TOPSIS yönteminin teknoloji şirketlerinin mali performansını hem sektör için hem de şirket bazında daha başarılı değerlendirilmesine olanak sağladığı belirtilmiştir (Dumanoğlu \& Ergül, 2010: 101-111).

Ömürbek ve Kınay (2013); çalışmalarından Borsa İstanbul'da faaliyet gösteren bir havayolu şirketi ile Frankfurt Menkul Kıymetler Borsası'nda faaliyet gösteren bir havayolu taşımacılı̆g şirketini 2012 y1lı için finansal verilerden elde edilen kriterlerle TOPSIS yöntemini uygulayarak performanslarını değerlendirmişlerdir. Farklı kriterlerde ayrı ayrı üstünlükleri olan iki şirketin genel değerlendirmesinde Borsa İstanbul'da faaliyet gösteren bir havayolu şirketinin performansı diğer şirkete göre üstün bulunmuştur (Ömürbek \& Kınay, 2013: 343-363).

Ertuğrul ve Özçil'in yapmış oldukları uygulamalı çalışmada, klima seçim problemi ÇKKV yöntemlerinden TOPSIS ve VIKOR yöntemleri uygulanarak, yöntemlerden elde edilen sonuçlar karşılaştırılarak değerlendirilmiştir (Ertuğrul \& Özçil, 2014: 267-282). Tunca vd. birçok nitel ve nicel kriter göz önünde bulundurularak en uygun muhasebe paket programı seçimini ikili üstünlüklere göre değerlendirme yapan ELECTRE ve AHP temelli TOPSIS yöntemlerini kullanarak değerlendirmiştir (Tunca vd., 2015: 53-71).

Günay ve Ünal (2016) ise çalışmalarında AHP ve TOPSIS yöntemlerinden faydalanarak bir telekomünikasyon şirketi üzerine yapmış oldukları çalışmada tedarikçi seçiminde en önemli kriterin ürün kalitesi olarak belirlemişlerdir (Günay \& Ünal, 2016: 37-53).

Ayan vd. (2017) çalışmalarında, sürdürülebilir kalkınmanın boyutlarından olan ekonomik boyuta göre Türkiye dâhil Avrupa ve Orta Asya ülkelerini kümeleme analizi ile TOPSIS yöntemi kullanarak konumlandırmışlardır. Ekonomik açıdan birbirine benzer ülkeleri kümeleme analizi ile belirlerken, kümeleme analizinin bulgularından kümeler arası ya da küme içi göreli üstünlük 
değerlendirmeler hakkına net bir bulgu edinemediklerinden çalışmada TOPSIS yönteminden de faydalanılmıştır. Uygulama sonucunda kümeleme ve TOPSIS analizlerinden elde edilen bulguların birbirleri ile tamamen tutarlı olduğu saptanmıştır (Ayan vd., 2017: 202-213).

Türkoğlu (2018) çalışmasında 2010-2014 dönemi için, ülkelerin sağlık politikalarının oluşturulması sürecine katkı sağlamak amaciyla 26 Avrupa ülkesini sağlık göstergelerini dikkate alarak TOPSIS yöntemiyle sıralamıştır. Çalışma sonucunda Norveç, Lüksemburg, Avusturya, İsveç ve Almanya'nın bu sıralamada ilk sıralarda yer aldıkları gözlemlenmiştir (Türkoğlu, 2018: 65-78).

Deste ve Şimşek (2019) çalışmalarında havayolu yolcu taşımacılığı sektöründe faaliyet göstermekte olan şirketlerin birbirleri arasındaki göreceli lojistik performans düzeylerinin belirlenmesini TOPSIS yöntemi ile değerlendirmişlerdir (Deste \& Şimşek, 2019: 395-411). Çalışmada üç farklı ağırlıklandırma yöntemi uygulanmıştır. Bunlardan biri entropi, diğeri basit ağırlıklı ortalama ve son olarak tercih ettikleri yöntem ise alanında uzman olan kişilerden görüş almaktır. Entropi ve uzman görüşlerinden aynı bulgular elde edilmiştir.

TOPSIS yönteminin birçok alanda uygulanmasının başlıca nedenleri; yapısının basit ve anlaşılır olması, kullanım kolaylığı, geliştirilebilir olması ve kriterlerin sayısının artmasıyla yöntemdeki hesaplama basamaklarının sayısının artmamasıdır. Bu nedenler yöntemin avantajları olarak da dikkate alınır. Yöntemin dezavantajları ise kullanılan Öklid uzaklığın, kriterler arasındaki ilişkiyi dikkate almamasıdır (Velasquez \& Hester, 2013: 56-66).

$\mathrm{Bu}$ çalışmada ise ÇKKV yöntemlerinden olan TOPSIS yönteminin uygulanırken dikkate alınması gereken önemli bir özelliğinin varsayımsal bir senaryo üzerinden incelenerek hangi durumlarda kullanılmasının daha uygun olabileceği araştırılmıştır. Bir başka ifade ile bu durum dikkate alınarak bu yöntemin kullanılmasının ya da hangi durumlarda kullanılmasının daha verimli olabileceği vurgulanmak istenmiştir.

\section{TOPSIS Yöntemi}

Tüm ÇKKV yöntemleri için başlangıçta amacın ve bu amaç doğrultusunda değerlendirme kriterlerinin belirlenmesi gerekir. Bir başka ifade ile üstünlükleri sıralanacak tüm alternatifler ve alternatiflerin karşılaștırılacağı değerlendirme kriterleri belirlenir. TOPSIS yöntemi aşağıdaki adımları takip etmektedir (Jahanshahloo vd., 2006) ve Chen ve Hwang tarafindan 1992 yılında ortaya konulmuştur (Chen \& Hwang, 1992: 1099-1119).

Adım 1: Karar Matrisinin Oluşturulması: $K_{m \times n}$

Üstünlükleri sıralanmak istenen karar alternatifleri karar matrisinin satırlarında, karar vermede kullanılacak değerlendirme kriterleri ise karar matrisinin sütunlarında yer alır (Yaralığlu 2011).

$$
K_{m \times n}=\left[K_{i j}\right]=\left[\begin{array}{ccccc}
k_{11} & k_{12} & k_{13} & \ldots & k_{1 n} \\
k_{21} & k_{22} & k_{23} & \ldots & k_{2 n} \\
\ldots & \ldots & \ldots & \ldots & \ldots \\
k_{m 1} & k_{m 2} & k_{m 3} & \ldots & k_{m n}
\end{array}\right],
$$

Karar matrisi $m \times n$ boyutlu olup; $\mathrm{m}$ alternatifleri, $\mathrm{n}$ ise değerlendirme kriterleri belirtir.

Adım 2: Normalize Edilmiş Karar Matrisinin Oluşturulması: $N_{m \times n}$

$\mathrm{Bu}$ matris karar matrisi ile aynı boyutta olup, aşağıdaki gibi hesaplanır.

$$
N_{m \times n}=\left[N_{i j}\right]=\left[\begin{array}{ccccc}
n_{11} & n_{12} & n_{13} & \ldots & n_{1 n} \\
n_{21} & n_{22} & n_{23} & \ldots & n_{2 n} \\
\ldots & \ldots & \ldots & \ldots & \ldots \\
n_{m 1} & n_{m 2} & n_{m 3} & \ldots & n_{m n}
\end{array}\right]
$$




$$
n_{i j}=\frac{k_{i j}}{\sqrt{\sum_{j=1}^{m} k_{i j}^{2}}}, \mathrm{i}=1,2,3, \ldots, \mathrm{m} . \mathrm{ve} \mathrm{j}=1,2,3, \ldots, \mathrm{n} .
$$

Adım 3: Ağırlıklı Karar Matrisinin Oluşturulması: $V_{m \times n}$

A ğırlıklı karar matrisi ise normalize karar matrisinden yararlanılarak elde edilir. Normalize edilmiş karar matrisinin sütunları, değerlendirme kriterlerine verilen ağırlık değerleri ile çarpılır (Çalışkan vd., 2012: 36). Ağırlıkların belirlenmesi için bazı yöntemler kullanılabilir ama karar probleminin yapısına göre, örneğin sıralanması hedeflenen alternatifler bir kişi ya da bir firma içinse, değerlendirme kriterlerine saptanan ağırlıklar kişiden kişiye ya da firmadan firmaya hatta belki aynı kişi ya da firma için zamanda değişebilecektir. Ağırlıkların belirlenmesinde karar vericinin sübjektif görüşleri yer alır (Demireli, 2010: 105).

Herhangi bir $\mathrm{j}$ değeri için; $\mathrm{j}$. değerlendirme kriterinin ağırlığını (önem derecesini) $w_{j}$ ile ifade edersek, $w_{1}+w_{2}+\cdots+w_{n}=1$ olur. Karar matrisi ve normalize karar matrisi ile aynı boyutta olan ağırlıklı karar matrisi aşağıdaki gibi hesaplanır.

$$
V_{m \times n}=\left[v_{i j}\right]=\left[\begin{array}{ccccc}
v_{11} & v_{12} & v_{13} & \ldots & v_{1 n} \\
v_{21} & v_{22} & v_{23} & \ldots & v_{2 n} \\
\ldots & \ldots & \ldots & \ldots & \ldots \\
v_{m 1} & v_{m 2} & v_{m 3} & \ldots & v_{m n}
\end{array}\right]=\left[\begin{array}{ccccc}
w_{1} n_{11} & w_{2} n_{12} & w_{3} n_{13} & \ldots & w_{n} n_{1 n} \\
w_{1} n_{21} & w_{2} n_{22} & w_{3} n_{23} & \ldots & w_{n} n_{2 n} \\
\ldots & \ldots & \ldots & \ldots & \ldots \\
w_{1} n_{m 1} & w_{2} n_{m 2} & w_{3} n_{m 3} & \ldots & w_{n} n_{m n}
\end{array}\right]
$$

Adım 4: Pozitif İdeal ve Negatif İdeal Çözümlerinin Oluşturulması: $\left(A^{+}, A^{-}\right)$

Pozitif ideal çözüm setinin oluşturulabilmesi için V matrisinin sütun değerlerinin en büyükleri seçilir. Sütunlar değerlendirme kriterlerini ifade ettiğinden, eğer sütundaki değerlendirme kriteri için en büyük olmak en iyi ise bu sütunun en büyüğü seçilir, aksi halde en küçüğü seçilir. Pozitif ideal çözüm seti aşağıdaki eşitlik yardımıyla oluşturulur.

$$
A^{+}=\left\{v_{1}^{+}, v_{2}^{+}, \ldots, v_{n}^{+}\right\}, \text {where } v_{k}^{+}=\left(\left(\max _{i} v_{i j}, j \in J\right),\left(\min _{i} v_{i j}, j \epsilon J^{\prime}\right)\right)
$$

Negatif ideal çözüm setinin oluşturulabilmesi için $\mathrm{V}$ matrisinin sütun değerlerinin en küçükleri seçilerek aşağıdaki eşitlikten yararlanılır. Değerlendirme kriteri için küçük değere sahip olmak iyi bir durumu ifade ediyorsa, en büyük seçilir.

$$
A^{-}=\left\{v_{1}^{-}, v_{2}^{-}, \ldots, v_{n}^{-}\right\}, \text {where } v_{k}^{-}=\left(\left(\min _{i} v_{i j}, j \epsilon J\right),\left(\max _{i} v_{i j}, j \epsilon J^{\prime}\right)\right)
$$

Adım 5: Ayırım Ölçütlerinin Hesaplanması: $\left(S_{i}^{+}, S_{i}^{-}\right)$

Ayırım ölçütlerinin hesaplanması için Öklid Uzaklık Yaklaşımı'ndan yararlanılmaktadır.

$$
S_{i}^{+}=\sqrt{\sum_{j=1}^{n}\left(v_{i j}-v_{j}^{+}\right)^{2}} \text { ve } S_{i}^{-}=\sqrt{\sum_{j=1}^{n}\left(v_{i j}-v_{j}^{-}\right)^{2}}
$$

Adım 6: İdeal Çözüme Göreli Yakınlığın Hesaplanması: $C_{i}$

$$
C_{i}=\frac{S_{i}^{-}}{S_{i}^{-}+S_{i}^{+}}, \text {where } 0 \leq C_{i} \leq 1
$$

$C_{i}^{\prime}$ 'nin 1'e eşit olması ilgili alternatifin pozitif ideal çözüm noktasında bulunduğunu, 0 'a eşit olması ise ilgili alternatifin negatif ideal çözüm noktasında bulunduğunu gösterir (Özdağoğlu 2012: 551).

Ad1m 7: Alternatiflerin Siralanmas1

6. adımda hesaplanan ideal çözüme göreli yakınlık değerleri en büyükten en küçüğe doğru sıralandığı taktirde alternatifler en iyiden en kötüye doğru sıralanmış olur. 


\section{TOPSIS Yönteminin Uygulanması}

Çalışma kapsamında varsayımsal olarak tanımlanan ÇKKV problemi; işe alım sürecinde bir yöneticinin $\mathrm{A}, \mathrm{B}, \mathrm{C}, \mathrm{D}$ ve $\mathrm{E}$ kişilerini $\mathrm{C}_{1}, \mathrm{C}_{2}, \ldots, \mathrm{C}_{10}$ olarak önceden belirlenen değerlendirme kriterleri doğrultusunda, en iyi kişiyi işe almayı ya da en iyi ilk iki kişi (n kişi) ile mülakat yaparak, mülakat sonuçlarını değerlendirdikten sonra işe alım sürecini sonlandırmayı planlamak üzerine tasarlanmıştır. Bir başka ifade ile yöneticinin karşılaştı̆̆ı sorunsal potansiyel adayları belirli kriterler doğrultusunda en iyiden en kötüye doğru sıralayarak işe en uygun adayın seçilmesini sağlamaktır. $\mathrm{Bu}$ ve buna benzer senaryolar işe alım süreçlerinde ve/veya performans değerlendirilmelerinde literatürde sıkça karşılaşılan sorunsallar arasında yer alır.

Uygulamada kişilerin performanslarının değerlendirilmesinde kullanılacak performans göstergelerinin yani kriterlerin ağırlıkları (önem dereceleri) aynı değildir. Varsayımsal senaryoda A, $B$ ve C kişilerinin değerlendirme kriterlerinden aldıkları ağırlıklı ortalama puanlarının aynı olduğu, D kişisinin ağırlıklı ortalama puanının en yüksek ve E kişisinin ağılıklı ortalama puanının ise en düşük olduğu bir durum oluşturulmuştur.

Bu çalışmadaki ana amaç ağırlıklı ortalama puanları aynı olan kişilerin TOPSIS yöntemi ile yapılacak olan sıralamada farklı sırada yer aldığını belirtmek ve böyle bir durumun istenmediği yani ağırlıklı ortalamada aynı puan alınmasına rağmen, sıralamada farklı sırada bulunmasının tercih edilmediği durumlar için uygulanmamasını vurgulamaktır.

Adım 1: $\mathrm{Bu}$ adımda senaryoya uygun karar matrisi oluşturulur. 5 kişi, 10 farklı değerlendirme kriteri dikkate alınarak sıralanmak hedeflendiğinden, karar matrisi 5 satır ve 10 sütundan oluşturulur. Karar matrisinde yer alan değerler ise hedeflenen durumu vurgulamak için basit sayısal değerler arasından seçilmiştir. Tablo 1'de karar matrisi ile birlikte değerlendirme kriterlerinin ağırlıkları ve her kişi için kriterlerin ağırlıkları ile kriterlerden aldığı puanlar dikkate alınarak hesaplanan ağırlıklı ortalama puanları sunulmuştur. Kriterlerin ağırlıkları oluşturulurken ise bir kriterin önem derecesi ile birkaç kriterin önem derecelerinin toplamı aynı olarak seçilmiştir. Örneğin $C_{1}$ kriterinin önem derecesi \%35 iken, $C_{2}, C_{3}$ ve $C_{10}$ kriterlerinin toplam önem derecesi aynidir $(0,15+0,1+0,1)$.

Tablo 1: Karar Matrisi

\begin{tabular}{cccccccccccr}
\hline & $\mathbf{C}_{\mathbf{1}}$ & $\mathbf{C}_{\mathbf{2}}$ & $\mathbf{C}_{\mathbf{3}}$ & $\mathbf{C}_{\mathbf{4}}$ & $\mathbf{C}_{\mathbf{5}}$ & $\mathbf{C}_{\mathbf{6}}$ & $\mathbf{C}_{\mathbf{7}}$ & $\mathbf{C}_{\mathbf{8}}$ & $\mathbf{C}_{\mathbf{9}}$ & $\mathbf{C}_{\mathbf{1 0}}$ & A ğırlıklı Ort. \\
\hline A ğırlık & 0,35 & 0,15 & 0,10 & 0,05 & 0,025 & 0,025 & 0,025 & 0,025 & 0,15 & 0,10 & \\
$\mathbf{A}$ & 100 & 0 & 0 & 0 & 0 & 0 & 0 & 0 & 0 & 0 & $\mathbf{3 5}$ \\
$\mathbf{B}$ & 0 & 100 & 100 & 0 & 0 & 0 & 0 & 0 & 0 & 100 & $\mathbf{3 5}$ \\
$\mathbf{C}$ & 50 & 0 & 50 & 50 & 50 & 50 & 50 & 50 & 0 & 50 & $\mathbf{3 5}$ \\
$\mathbf{D}$ & 100 & 0 & 100 & 0 & 100 & 0 & 100 & 0 & 100 & 0 & 65 \\
$\mathbf{E}$ & 0 & 10 & 0 & 10 & 0 & 10 & 0 & 10 & 0 & 10 & 3,5 \\
\hline
\end{tabular}

Tablo 1'den de görüldüğü üzere, oluşturulan senaryoda $A, B$ ve C kişilerinin ağırlıklı ortalama puanları (35) aynı olup, D kişisi en yüksek ağırlıklı ortalama puana (65) ve E kişisi ise en düşük ağırlıklı ortalama puana $(3,5)$ sahiptir.

A kişisi \%35 önem derecesine sahip olan $\mathrm{C}_{1}$ kriterinden 100 puan almış, $\mathrm{B}$ kişisi ise sırasıyla $\% 15, \% 10$ ve \%10 önem derecelerine sahip olan $\mathrm{C}_{2}, \mathrm{C}_{3}$ ve $\mathrm{C}_{10}$ kriterlerinden 100 puan alarak $\mathrm{A}$ kişisiyle aynı ağırlıklı ortalamaya sahiptir. $\mathrm{C}$ kişisi de farklı önem dereceleri olan daha fazla kriterin her birinden daha az puan alarak A ve B kişileriyle aynı ağırlıklı ortalamaya sahiptir.

Adım 2: Tablo 1'de yer alan karar matrisinin sütunlarındaki her değer ilgili sütundaki değerlerin kareleri toplamının kareköküne bölünmesiyle tek paydaya indirgenerek Tablo 2'de yer alan normalize karar matrisi elde edilmiştir. 
Tablo 2: Normalize Karar Matrisi

\begin{tabular}{ccccccccccc}
\hline & $\mathbf{C}_{\mathbf{1}}$ & $\mathbf{C}_{\boldsymbol{2}}$ & $\mathbf{C}_{\mathbf{3}}$ & $\mathbf{C}_{\mathbf{4}}$ & $\mathbf{C}_{\mathbf{5}}$ & $\mathbf{C}_{\mathbf{6}}$ & $\mathbf{C}_{\mathbf{7}}$ & $\mathbf{C}_{\mathbf{8}}$ & $\mathbf{C}_{\mathbf{9}}$ & $\mathbf{C}_{\mathbf{1 0}}$ \\
\hline $\mathbf{A}$ & 0,67 & 0,00 & 0,00 & 0,00 & 0,00 & 0,00 & 0,00 & 0,00 & 0,00 & 0,00 \\
B & 0,00 & 1,00 & 0,67 & 0,00 & 0,00 & 0,00 & 0,00 & 0,00 & 0,00 & 0,89 \\
$\mathbf{C}$ & 0,33 & 0,00 & 0,33 & 0,98 & 0,45 & 0,98 & 0,45 & 0,98 & 0,00 & 0,45 \\
D & 0,67 & 0,00 & 0,67 & 0,00 & 0,89 & 0,00 & 0,89 & 0,00 & 1,00 & 0,00 \\
E & 0,00 & 0,10 & 0,00 & 0,20 & 0,00 & 0,20 & 0,00 & 0,20 & 0,00 & 0,09 \\
\hline
\end{tabular}

Adım 3: Tablo 1'de yer alan ağırlıklar ve Tablo 2'de yer alan normalize karar matrisi dikkate alınarak Tablo 3 'te yer alan ağırlıklı normalize karar matrisi elde edilmiştir. Bir sonraki adım için gerekli olan her bir sütunun maksimum ve minimum değerleri de hesaplanarak ağıllıklı karar matrisinin son iki satırına eklenerek Tablo 3'te sunulmuştur.

Tablo 3: A ğırlıklı Normalize Karar Matrisi

\begin{tabular}{ccccccccccc}
\hline & $\mathbf{C}_{\mathbf{1}}$ & $\mathbf{C}_{\mathbf{2}}$ & $\mathbf{C}_{\mathbf{3}}$ & $\mathbf{C}_{\boldsymbol{4}}$ & $\mathbf{C}_{\mathbf{5}}$ & $\mathbf{C}_{\mathbf{6}}$ & $\mathbf{C}_{\mathbf{7}}$ & $\mathbf{C}_{\mathbf{8}}$ & $\mathbf{C}_{\mathbf{9}}$ & $\mathbf{C}_{\mathbf{1 0}}$ \\
\hline $\mathbf{A}$ & 0,23 & 0,00 & 0,00 & 0,00 & 0,00 & 0,00 & 0,00 & 0,00 & 0,00 & 0,00 \\
$\mathbf{B}$ & 0,00 & 0,15 & 0,07 & 0,00 & 0,00 & 0,00 & 0,00 & 0,00 & 0,00 & 0,09 \\
$\mathbf{C}$ & 0,12 & 0,00 & 0,03 & 0,05 & 0,01 & 0,02 & 0,01 & 0,02 & 0,00 & 0,04 \\
D & 0,23 & 0,00 & 0,07 & 0,00 & 0,02 & 0,00 & 0,02 & 0,00 & 0,15 & 0,00 \\
$\mathbf{E}$ & 0,00 & 0,01 & 0,00 & 0,01 & 0,00 & 0,00 & 0,00 & 0,00 & 0,00 & 0,01 \\
Mak. & $\mathbf{0 , 2 3}$ & $\mathbf{0 , 1 5}$ & $\mathbf{0 , 0 7}$ & $\mathbf{0 , 0 5}$ & $\mathbf{0 , 0 2}$ & $\mathbf{0 , 0 2}$ & $\mathbf{0 , 0 2}$ & $\mathbf{0 , 0 2}$ & $\mathbf{0 , 1 5}$ & $\mathbf{0 , 0 9}$ \\
Min. & $\mathbf{0 , 0 0}$ & $\mathbf{0 , 0 0}$ & $\mathbf{0 , 0 0}$ & $\mathbf{0 , 0 0}$ & $\mathbf{0 , 0 0}$ & $\mathbf{0 , 0 0}$ & $\mathbf{0 , 0 0}$ & $\mathbf{0 , 0 0}$ & $\mathbf{0 , 0 0}$ & $\mathbf{0 , 0 0}$ \\
\hline
\end{tabular}

Adım 4 ve Adım 5: Ağırlıklı normalize karar matrisi ve tüm kriterler için kişilerin aldıkları maksimum ve minimum puanlar dikkate alınarak hesaplanan pozitif ideal ve negatif ideal değerler Tablo 4'ün son sütunun da sunulmuştur.

Tablo 4: Pozitif İdeal ve Negatif İdeal

\begin{tabular}{|c|c|c|c|c|c|c|c|c|c|c|c|}
\hline & $\mathrm{C}_{1}$ & $\mathrm{C}_{2}$ & $\mathrm{C}_{3}$ & $\mathrm{C}_{4}$ & $\mathrm{C}_{5}$ & $\mathrm{C}_{6}$ & $\mathrm{C}_{7}$ & $\mathrm{C}_{8}$ & $\mathrm{C}_{9}$ & $\mathrm{C}_{10}$ & Pozitif İdeal \\
\hline $\mathbf{A}$ & 0,00 & 0,02 & 0,00 & 0,00 & 0,00 & 0,00 & 0,00 & 0,00 & 0,02 & 0,01 & 0,25 \\
\hline B & 0,05 & 0,00 & 0,00 & 0,00 & 0,00 & 0,00 & 0,00 & 0,00 & 0,02 & 0,00 & 29 \\
\hline C & 0,01 & 0,02 & 0,00 & 0,00 & 0,00 & 0,00 & 0,00 & 0,00 & 0,02 & 0,00 & 0,25 \\
\hline D & 0,00 & 0,02 & 0,00 & 0,00 & 0,00 & 0,00 & 0,00 & 0,00 & 0,00 & 0,01 &, 18 \\
\hline $\mathbf{E}$ & 0,05 & 0,02 & 0,00 & 0,00 & 0,00 & 0,00 & 0,00 & 0,00 & 0,02 & 0,01 & 0,33 \\
\hline & $\mathbf{C}_{1}$ & $\mathrm{C}_{2}$ & $\mathrm{C}_{3}$ & $\mathrm{C}_{4}$ & $\mathrm{C}_{5}$ & $\mathrm{C}_{6}$ & $\mathrm{C}_{7}$ & $\mathrm{C}_{8}$ & $\mathrm{C}_{9}$ & $\mathrm{C}_{10}$ & Negatif İdeal \\
\hline $\mathbf{A}$ & 0,05 & 0,00 & 0,00 & 0,00 & 0,00 & 0,00 & 0,00 & 0,00 & 0,00 & 0,00 & 0,23 \\
\hline B & 0,00 & 0,02 & 0,00 & 0,00 & 0,00 & 0,00 & 0,00 & 0,00 & 0,00 & 0,01 & 0,19 \\
\hline C & 0,01 & 0,00 & 0,00 & 0,00 & 0,00 & 0,00 & 0,00 & 0,00 & 0,00 & 0,00 & 0,14 \\
\hline D & 0,05 & 0,00 & 0,00 & 0,00 & 0,00 & 0,00 & 0,00 & 0,00 & 0,02 & 0,00 & 0,29 \\
\hline $\mathbf{E}$ & 0,00 & 0,00 & 0,00 & 0,00 & 0,00 & 0,00 & 0,00 & 0,00 & 0,00 & 0,00 & 0,02 \\
\hline
\end{tabular}

Adım 6 ve Adım 7: Pozitif ideal ve negatif ideal setler yardımıyla hesaplanan ideal çözüme yakınlık değerleri ve bu değerler yarımıyla oluşan sıralama Tablo 5'te sunulmuştur.

Tablo 5: İdeal Çözüme Göre Yakınlık

\begin{tabular}{ccccc}
\hline & Pozitif İdeal & Negatif İdeal & İdeal Çözüme Göre Yakınlık & Sıralama \\
\hline A & 0,25 & 0,23 & 0,48 & 2 \\
B & 0,29 & 0,19 & 0,39 & 3 \\
C & 0,25 & 0,14 & 0,37 & 4 \\
D & 0,18 & 0,29 & 0,61 & 1 \\
E & 0,33 & 0,02 & 0,06 & 5 \\
\hline
\end{tabular}


Tablo 5'te yer alan ideal çözüme göre yakınlık değerlerinden D kişisinin en iyi, E kişisinin en kötü, A, B ve C kişilerinin ağırlıklı ortalama puanları aynı olmasına rağmen, A kişisinin ikinci, B kişisinin üçüncü, $C$ kişisinin ise dördüncü sırada yer aldığ 1 gözlemlenmiştir.

\section{Sonuç ve Değerlendirme}

ÇKKV; birden çok karar kriterini göz önünde bulundurarak alternatiflerin iyiden kötüye sıralanmasını, bazen karşılaştırılmasını ve bu sonuçların doğrultusunda alternatifler arasından seçim yapılmasını sağlayan karar analizi yöntemlerini içerir. Kriterlerin önem derecelerinin belirlenmesi, bu çalışmalarda önemli sorunsallardan biridir. Bu çalışmaların doğası gereği farklı önem dereceleri için farklı sonuçlar elde edilir.

$\mathrm{Bu}$ çalışmada, varsayımsal bir senaryo üzerinden personel seçimi sorunsalı ÇKKV yöntemlerinden TOPSIS ile değerlendirilmiştir. TOPSIS yöntemi kriterlerin birbirleriyle kıyaslanmasını dikkate almadan, pozitif ideal ve negatif ideal çözümlere yakınlığı dikkate alarak değerlendirme yapar. Bu değerlendirmeyi de uzaklık fonksiyonu yardımıyla belirler ve alternatifler arasındaki korelasyonu dikkate almaz.

Varsayımsal olarak oluşturulan karar probleminin amacı uygun personel seçimidir. Bu seçim 10 kritere göre beş kişi arasından gerçekleştirilmiştir. Uygulamada oluşturulan senaryoda D kişinin ilk sırada olması beklenilen bir sonuçtur, çünkü kişi çok daha fazla kriterden puan toplayarak diğer kişilerden üstün bir başarı elde etmiştir. E kişisi için de senaryo tam tersi yönde işlemektedir. Bu iki kişinin sıralamadaki yeri aşikardır. Ancak A, B ve C kișilerinin ağırlıklı ortalama puanları aynı olmasına rağmen; TOPSIS yöntemi ile yapılan değerlendirmede sadece önem derecesi fazla olan tek bir kriterden puan alan kişi, sıralamada daha üst sırada yer almaktadır. Burada dikkat edilmesi gereken nokta, araştırmayı yapan kişinin ya da karar vericinin bu durumu göz önünde bulundurarak uygulamada bu yöntemi tercih etmesidir.

Aslında bu örnek ÇKKV yöntemlerinden hangisinin hangi durumlarda uygulanması gerektiğini de vurgular. Bu açıdan bakıldığında ise bu tarz sıralamanın istenmediği durumlarda, bu yöntemin tercih edilmemesi gerekir. Ayrıca bu bulgulardan elde edilen bir diğer yaklaşım ise, benzer yöntemlerin seçiminde ya da yöntemlerin karşılaştırıldığ çalışmalarda, sadece bulgulardan elde edilen sonuçların karşılaştırılarak karar verilmemesi gerektiğini vurgulanmaktır.

\section{Kaynakça}

Ayan, Yakıcı, T., Ünal, H., \& Samut, S. (2017). A comparative analysis of european and central asian countries from the economic dimension of sustainable development: cluster analysis and TOPSIS method. Route Educational and Social Science Journal, 4(16): 202-213. http://dx.doi.org/10.17121/ressjournal.772

Chen, S. J., \& Hwang, C. L. (1992). Fuzzy multiple attribute decision making methods. In Fuzzy multiple attribute decision making (pp. 289-486). Springer, Berlin, Heidelberg.Cho, K. T. (2003). Multicriteria decision methods: an attempt to evaluate and unify. Mathematical and Computer Modelling, 37(9-10), 1099-1119.

Cho, K. T. (2003). Multicriteria decision methods: an attempt to evaluate and unify. Mathematical and computer modelling, 37(9-10), 1099-1119.

Çalışkan, H., Kurşuncu, B., Kurbanoğlu, C., \& Güven, Ş. Y. (2012). TOPSIS metodu kullanılarak kesici takım malzemesi seçimi. Makine Teknolojileri Elektronik Dergisi, 9(3), 35-42. https://doi.org/10.17065/huniibf.340696 
Çınar, N. T. (2010). Kuruluş yeri seçiminde bulanık TOPSIS yöntemi ve bankacılık sektöründe bir uygulama. Karamanoğlu Mehmetbey Üniversitesi Sosyal ve Ekonomik Araştırmalar Dergisi, (1), 37-45. https://dergipark.org.tr/tr/pub/kmusekad/issue/10218/125604

Deste, M., \& Şimşek, A. İ. (2019). Havayolu yolcu taşımacılığı sektöründeki şirketlerin lojistik performans açısından entropi ve TOPSIS yöntemleri kullanılarak karşılaştırılması. Yönetim ve Ekonomi Araştırma Dergisi, 17(1), 395-411. $\mathrm{http} / / / \mathrm{dx}$. doi.org/10.11611/yead.483926

Demireli, E. (2010). TOPSIS çok kriterli karar verme sistemi: Türkiye'deki kamu bankaları üzerine bir uygulama. Girişimcilik ve Kalkınma Dergisi, 5(1), 101-112. https://dergipark.org.tr/tr/pub/girkal/issue/45195/565962

Dumanoğlu, S., \& Ergül, N. (2010). İMKB'de işlem gören teknoloji şirketlerinin mali performans ölçümü. Muhasebe ve Finansman Dergisi, (48), 101-111. https://dergipark.org.tr/tr/pub/mufad/issue/35627/396007

Ertuğrul, İ., \& Karakaşoğlu, N. (2009). Performance evaluation of Turkish cement firms with fuzzy analytic hierarchy process and TOPSIS methods. Expert Systems with Applications, 36(1), 702. https://doi.org/10.1016/j.eswa.2007.10.014

Ersöz, F., \& Kabak, M. (2010). Savunma sanayi uygulamalarında çok kriterli karar verme yöntemlerinin literatür araştırması. Savunma Bilimleri Dergisi,9(1), 97-125. https://dergipark.org.tr/tr/pub/khosbd/issue/19228/204327

Ertuğrul, İ., \& Özçil, A. (2014). Çok kriterli karar vermede TOPSIS ve VIKOR yöntemleriyle klima seçimi. Çankırı Karatekin Üniversitesi İIBF Dergisi, 4(1), 267-282. https://dergipark.org.tr/tr/pub/ckuiibfd/issue/32902/365512

Günay, Z., \& Ünal, Ö. F. (2016). AHP-TOPSIS yöntemi ile tedarikçi seçimi (Bir telekomünikasyon şirketi örneği). PESA Uluslararası Sosyal Araştırmalar Dergisi, 2(1), 37-53. https://dergipark.org.tr/tr/pub/farabi/issue/46925/560429

Hwang, C. L., \& Yoon, K. (1981). Methods for multiple attribute decision making. In Multiple attribute decision making (pp. 58-191). Springer, Berlin, Heidelberg.

Jahanshahloo, G. R., Lotfi, F. H., \& Izadikhah, M. (2006). An algorithmic method to extend TOPSIS for decision-making problems with interval data. Applied Mathematics And Computation, 175(2), 1375-1384.

Koyuncu, O., \& Özcan, M. (2014). Personel seçim sürecinde analitik hiyerarşi süreci ve TOPSIS yöntemlerinin karşılaştırılması: Otomotiv sektöründe bir uygulama. Hacettepe Üniversitesi İktisadi ve İdari Bilimler Fakültesi Dergisi, 32(2), 195-218. https://doi.org/10.17065/huiibf.14332

Opricovic, S., \& Tzeng, G. H. (2004). Compromise solution by MCDM methods: A comparative analysis of VIKOR and TOPSIS. European Journal Of Operational Research, 156(2), 445455. https://doi.org/10.1016/S0377-2217(03)00020-1

Ömürbek, V., \& Kınay, B. (2013). Havayolu taşımacılığı sektöründe TOPSIS yöntemiyle finansal performans değerlendirmesi. Süleyman Demirel Üniversitesi İktisadi ve İdari Bilimler Fakültesi Dergisi, 18(3), 343-363.

Özdağoğlu, A. (2012). Üretim yapan işletmeler için hidrolik giyotin alternatiflerinin TOPSIS yöntemi ile incelenmesi. Ege Akademik Bakış, 12(4), 549-562.

https://dergipark.org.tr/tr/pub/eab/issue/39902/473802 
Çok Kriterli Karar Verme Yöntemlerinin Seçimi Üzerine Bir Değerlendirme: TOPSIS Örneği 2081

Özdağoglu, A. (2013). Farkli normalizasyon yöntemlerinin TOPSIS'te karar verme sürecine etkisi/The effects of dfferent normalization eethods to decision making process in TOPSIS. Ege Akademik Bakis, 13(2), 245-257. https://dergipark.org.tr/tr/pub/eab/issue/39918/474122

Özdemir, A. İ., \& Seçme, N. Y. (2009). İki aşamalı stratejik tedarikçi seçiminin bulanık topsis yöntemi ile analizi. Afyon Kocatepe Üniversitesi Iktisadi ve İdari Bilimler Fakültesi Dergisi, 11(2), 79-112. https://dergipark.org.tr/tr/pub/akuiibfd/issue/1626/20372

Özkan, Ö. (2007). Personel seçiminde karar verme yöntemlerinin incelenmesi: AHP, ELECTRE ve TOPSIS örneği. Basılmamış Yüksek Lisans Tezi, Dokuz Eylül Üniversitesi, Sosyal Bilimler Enstitüsü.

Uzun, S., \& Kazan, H. (2016). Çok kriterli karar verme yöntemlerinden AHP TOPSIS ve PROMETHEE karşılaştırılması: gemi inşada ana makine seçimi uygulaması. Journal of Transportation and Logistics, 1(1), 99-113. http://dx.doi.org/10.22532/jtl.237889

Tunca, M., Aksoy, E., Bülbül, H., \& Ömürbek, N. (2015). AHP temelli TOPSIS ve ELECTRE yöntemleri ile muhasebe paket programı seçimi. Niğde Üniversitesi İktisadi ve İdari Bilimler Fakültesi Dergisi, 8(1), 53-71. https://dergipark.org.tr/tr/pub/niguiibfd/issue/19757/211524

Türkmen, S. Y., \& Çağıl, G. (2012). İMKB'ye kote bilişim sektörü şirketlerinin finansal performanslarının TOPSIS yöntemi ile değerlendirilmesi. Maliye ve Finans Yazılarl, 1(95), 59-78. https://dergipark.org.tr/tr/pub/mfy/issue/16285/17078

Türkoğlu, S. P. (2018). Avrupa ülkelerinin sağlık göstergelerinin topsıs yöntemi ile değerlendirilmesi. Abant İzzet Baysal Üniversitesi Sosyal Bilimler Enstitüsü Dergisi. https://doi.org/10.11616/asbed.v18i38800.459468

Velasquez, M., \& Hester, P. T. (2013). An analysis of multi-criteria decision making methods. International Journal of Operations Research, 10(2), 56-66.

Yaralığlu, K. (2011). TOPSIS yönetimi, Dokuz Eylül Üniversitesi web sitesi.

Wang, J. J., Jing, Y. Y., Zhang, C. F., \& Zhao, J. H. (2009). Review on multi-criteria decision analysis aid in sustainable energy decision-making. Renewable and sustainable energy reviews, 13(9), 2263-2278. https://doi.org/10.1016/j.rser.2009.06.021

Wang, Y. J. (2009). Combining grey relation analysis with FMCGDM to evaluate financial performance of Taiwan container lines. Expert Systems with Applications, 36(2), 2424-2432. https://doi.org/10.1016/j.eswa.2007.12.027 